\title{
IMPLEMENTASI MANAJEMEN MUTU TERPADU DI SDIT INSAN MANDIRI JAKARTA
}

\author{
Implementation of Total Quality Management at SDIT Insan Mandiri Jakarta
}

\section{KHOIRUNNISA ${ }^{1}$}

\begin{abstract}
This thesis aims to evaluate the implementation of Total Quality Management (TQM), covering the customer satisfaction and continuous improvement at SDIT Insan Mandiri Jakarta. Evaluation is conducted by studying customer's perception both internals and externals. This research applies qualitative approach with a case study method. The data were collected through observation, interview, and studying related documents and recordings This research starts from February until July 2013. The findings of the research are: overall, implementation of TQM has increase customer satisfaction and encourage continuous improvement at SDIT Insan Mandiri. Those TQM aspects work effectively since management of SDIT Insan Mandiri Jakarta implemented Total Quality Management. The findings lead to the recommendation that (1) The management should build more facilities to support learning activities to enhance customer satisfaction, (2) SDIT Insan Mandiri should conduct comparative studies to broaden their horizons and compare their advantages and disadvantages to other schools.
\end{abstract}

Keywords: Total Quality Management, customer satisfaction and continous improvement.

\section{PENDAHULUAN}

Perkembangan ilmu pengetahuan dan teknologi telah membawa perubahan di hampir semua aspek kehidupan manusia dimana berbagai permasalahan hanya dapat dipecahkan kecuali dengan upaya penguasaan dan peningkatan ilmu pengetahuan dan teknologi. Selain manfaat bagi kehidupan manusia di satu sisi perubahan tersebut juga telah membawa manusia ke dalam era persaingan global yang semakin ketat. Agar mampu berperan dalam persaingan global, maka sebagai bangsa Indonesia, kita perlu terus mengembangkan dan meningkatkan kualitas sumber daya manusia.

Mengenai kualitas sumber daya manusia, pendidikan memegang peran yang sangat penting. Peningkatan kualitas pendidikan merupakan suatu proses yang terintegrasi dengan proses peningkatan kualitas sumber daya manusia itu sendiri. Maka pemerintah bersama kalangan swasta bersama-sama telah dan terus berupaya mewujudkan amanat tersebut melalui berbagai usaha pembangunan pendidikan yang lebih berkualitas melalui pengembangan dan perbaikan kurikulum dan sistem evaluasi, perbaikan sarana pendidikan, pengembangan dan pengadaan materi ajar, serta pelatihan bagi guru dan tenaga kependidikan lainnya. Tetapi pada kenyataannya upaya pemerintah tersebut belum cukup berarti dalam meningkatkan kuailtas pendidikan.

Masalah utama dalam dunia pendidikan adalah kegagalan manajemen dalam menyusun perencanaan ke depan. Perencanaan tersebut, bukan merupakan serangkaian langkah untuk menerapkan mutu tapi lebih merupakan desakan serius terhadap manajemen tentang apa yang harus dan tidak boleh dilakukan agar pendidikan berhasil dengan baik.

Banyak juga masalah mutu yang dihadapi dalam dunia pendidikan, seperti mutu lulusan, mutu pengajaran, bimbingan dan latihan dari guru, mutu

\footnotetext{
${ }^{1}$ Guru di SDIT Insan Mandiri Jakarta
} 
profesionalisme dan kinerja guru, mutu-mutu tersebut terkait dengan mutu manajerial para pimpinan pendidikan, keterbatasan dana, sarana prasarana, fasilitas pendidikan, media, sumber belajar, alat dan bahan latihan, iklim sekolah, lingkungan pendidikan serta dukungan dari pihak-pihak yang terkait dengan pendidikan. Memang semua kelemahan mutu dari komponen-komponen pendidikan tersebut akhirnya berujung pada rendahnya mutu lulusan.

Tujuan akhir dari suatu organisasi adalah output dan outcome yang bermutu tinggi. Untuk mendapatkan hasil yang demikian maka sekolah harus menerapkan suatu model manajemen mutu yang dikenal dengan Total Quality Management (TQM) atau Manajemen Mutu Terpadu. Manajemen Mutu Terpadu merupakan proses perbaikan secara terus menerus atau berkesinambungan yang dilakukan oleh sekolah dalam rangka mencapai sekolah yang bermutu.

Kepala sekolah sebagai manajemen puncak berperan penting dalam suksesnya pelaksanaan implementasi Manajemen Mutu Terpadu (TQM) di sekolah. Konsep sekolah bermutu (unggul) perlu ada dalam konsep setiap kepala sekolah. Kepala sekolah perlu memahami TQM sebagai suatu falsafah, metode, teknik dan strategi manajemen untuk perbaikan mutu sekolah, karena kinerja organisasi sekolah senantiasa dinilai masyarakat dalam situasi yang semakin maju seperti sekarang ini. Kepala Sekolah dan para guru perlu memahami harapan masyarakat terhadap sekolahnya.

Dunia pendidikan yang selama ini dinilai kurang mampu menghasilkan lulusan yang berkualitas secara ilmiah dan religius masih mendapat sorotan tajam dari kalangan pemerhati pendidikan Islam. Dalam satu sisi pendidikan formal hanya terfokus untuk menghasilkan anak didik yang mempunyai nilai matematika, bahasa inggris, ilmu sains, bahasa Indonesia, dan semua pelajaran sains dan teknologi yang bagus. Sampai pemerintah menerapkan nilai standar kelulusan secara nasional. Dan pelajaran agama tidak masuk dalam standar kelulusan.

Dari gambaran itulah kemudian muncul konsep sekolah Islam terpadu yang mempunyai tujuan menciptakan anak didik yang mempunyai keseimbangan penguasaan ilmu dunia (seperti sekolah pada umumnya) dan ilmu agama Islam. Dengan kata lain, hadirnya sekolah Islam terpadu mempunyai misi dan visi penggabungan sekolah umum dengan pondok pesantren. Dengan adanya sekolah Islam terpadu, membuat masyarakat menaruh banyak harapan cemerlangnya masa depan Indonesia. Dari lulusan sekolah Islam terpadu diharapkan mampu mencetak generasi yang akan memimpin bangsa ini dengan akhlak mulia dan cerdas.

Dari sejumlah sekolah dasar yang telah menerapkan Manajemen Mutu Terpadu, Sekolah Dasar Islam Terpadu Insan Mandiri Jakarta dipilih sebagai objek penelitian. Alasannya adalah pertama, SDIT Insan Mandiri Jakarta diakui sebagai sekolah model terbaik di tingkat nasional yang aktif mewujudkan insan mandiri, cerdas, kreatif, peduli dan berakhlak mulia. Kedua, SDIT Insan Mandiri Jakarta memiliki visi, misi dan tujuan pendidikan yang searah dengan Standar Nasional Pendidikan dan Standar Sekolah Dasar Islam Terpadu. Dan memiliki tujuan melaksanakan Total Quality Management di SDIT Insan Mandiri.

Penelitian ini akan fokus untuk mengungkap bagaimana Total Quality Management dapat diterapkan dengan baik di Sekolah Dasar Islam Terpadu Insan Mandiri Jakarta. Dan yang menjadi sub fokus penelitian ini dibatasi pada aspek-aspek sebagai berikut, yaitu: 1) kepuasan pelanggan dan 2) perbaikan berkesinambungan.

Secara umum penelitian ini bertujuan memperoleh pemahaman menyeluruh tentang implementasi Manajemen Mutu Terpadu di SDIT Insan Mandiri dalam rangka pencapaian sebagai sekolah model terbaik di tingkat nasional. Sedangkan tujuan khusus 
dari penelitian ini bertujuan memberikan gambaran yang komprehensif tentang pelaksanaan Manajemen Mutu Terpadu di SDIT Insan Mandiri Jakarta, kepuasan pelanggan dalam implementasi Manajemen Mutu Terpadu di SDIT Insan Mandiri Jakarta, perbaikan berkesinambungan dalam implementasi Manajemen Mutu Terpadu di SDIT Insan Mandiri Jakarta.

\section{Total Quality Management (TQM)}

Menurut James dan William, mutu terpadu (2008:19),"total quality is based on three fundamental principles: first, a focus on customers and stakeholders. Second, participation and teamwork by everyone in the organization. Third, a process focus supported by continuous improvement and learning. Ada tiga prinsip pokok dalam mutu terpadu; pertama, fokus pada pelanggan dan stakeholders. Kedua, partisipasi dan tim kerja oleh setiap orang dalam organisasi. Ketiga, proses fokus yang didukung oleh perbaikan terus menerus dan pembelajaran.

Menurut Sallis (2002:24),"TQM is a practical but strategic approach to running an oranization that focuses on the needs of its customers and clients . . It can be thought of as a philosophy of continual improvement only achievable by and through people". TQM adalah sebuah pendekatan praktis, namun strategis, dalam menjalankan roda organisasi yang memfokuskan diri pada kebutuhan pelanggan dan kliennya. TQM dapat dipahami sebagai sebagai fiosofi perbaikan tanpa henti hingga tujuan organisasi dapat dicapai dan dengan melibatkan segenap komponen dalam organisasi tersebut.

TQM menurut Mullins (2005:964), "one particular approach to improved organisational performance and effectiveness is the concept of the Japanese-inspired Total Quality Management (TQM). There are numerous definitions of TQM. These definitions are generally expressed in terms of: a way of life for an organisation as a whole, committed to total customer satisfaction through a continuous process of improvement, and the contribution and involvement of people." Salah satu pendekatan tertentu untuk meningkatkan kinerja organisasi dan efektivitas adalah konsep Jepang-Manajemen Mutu Terpadu (TQM). Ada berbagai definisi TQM. Definisi ini umumnya dinyatakan dalam hal: cara hidup sebuah organisasi secara keseluruhan, berkomitmen untuk kepuasan pelanggan melalui proses perbaikan berkesinambungan, dan kontribusi dan keterlibatan masyarakat

Menurut Mukhneri Mukhtar (2011:40), "mutu manajemen secara menyeluruh adalah pengelolaan organisasi dengan bermacam-macam kesempatan untuk perbaikan secara terus menerus kualitas produksi maupun kebutuhan pelanggan."

Dapat disimpulkan bahwa manajemen mutu terpadu adalah suatu filosofi perbaikan, yang dapat menyediakan berbagai lembaga pendidikan dengan sekumpulan alat-alat praktis untuk penyesuaian dan pemenuhan harapan, keinginan, dan kebutuhan pelanggan sekarang dan masa depan.

Pembahasan mengenai metode Total Quality Management difokuskan pada tiga pakar utama yang merupakan pionir dalam pengembangan Total Quality Management. Mereka adalah W. Edwards Deming, Joseph M. Juran, dan Philip B. Crosby.

Kepemimpinan adalah unsur penting dalam Total Quality Management. Pemimpin harus memiliki visi dan mampu menerjemahkan visi tersebut ke dalam kebijakan yang jelas dan tujuan yang spesifik. Dalam konsep TQM, memimpin berarti menentukan hal-hal yang tepat untuk dikerjakan, menciptakan dinamika organisasi yang dikehendaki agar semua orang memberikan komitmen, bekerja dengan semangat dan antusias untuk mewujudkan hal-hal yang telah ditetapkan. Memimpin berarti juga dapat mengkomunikasikan visi dan prinsip organisasi kepada bawahan. Kegiatan memimpin termasuk kegiatan menciptakan budaya atau kultur positif dan iklim yang 
harmonis dalam lingkungan lembaga atau organisasi, serta menciptakan tanggung jawab dan pemberian wewenang dalam pencapaian tujuan bersama.

Kepuasan pelanggan adalah suatu tanggapan emosional pada evaluasi terhadap pengalaman konsumsi suatu produk atau jasa. Kepuasan pelanggan adalah tingkat perasaan seseorang setelah membandingkan kinerja (atau hasil) yang ia rasakan dibandingkan dengan harapannya. Dalam Manajemen Mutu Terpadu, konsep mengenai kualitas dan pelanggan diperluas.

Kualitas tidak hanya bermakna kesesuaian dengan spesifikasi-spesifikasi tertentu, tetapi kualitas tersebut ditentukan oleh pelanggan. Pelanggan itu sendiri meliputi pelanggan internal dan eksternal. Kebutuhan pelanggan diusahakan untuk dipuaskan dalam segala aspek. Dalam pendidikan yang dimaksud dengan pelanggan internal adalah guru dan staff. Sedangkan pelanggan eksternal adalah pelajar, orang tua dan masyarakat umum. Manajemen Mutu Terpadu menganut tolok ukur keberhasilan sekolah yang ketat, yaitu berupa tingkat kepuasan pelanggan internal dan eksternal. Sekolah disebut berhasil jika sekolah tersebut mampu memberikan layanan sama atau melebihi harapan-harapan pelanggan.

Perbaikan berkesinambungan, merupakan salah satu unsur paling fundamental dari Total Quality Management. Perbaikan berkelanjutan adalah berupa komitmen (Perbaikan Mutu Berkelanjutan atau CQI) maupun proses (Perbaikan Proses Berkelanjutan atau CPI). Komitmen terhadap mutu dilakukan dalam bentuk suatu pernyataan dedikasi untuk saling berbagi visi dan misi dan pemberdayaan semua partisipan untuk bergerak bersama-sama mencapai visi yang telah ditetapkan.

Salah satu model manajemen yang dapat digunakan adalah model manajemen PDCA (Plan, Do, Check, Action) yang akan menghasilkan pengembangan berkelanjutan (continuous improvement) atau kaizen mutu sebagaimana yang terlihat dalam Siklus Deming (Deming Cycle) pada gambar di atas. Siklus Deming adalah model perbaikan berkesinambungan yang dikembangkan oleh W. Edward Deming yang terdiri atas empat komponen utama secara berurutan.

\section{Kepuasan Pelanggan}

Menurut Edward Sallis (2002:29), "staff have to understand how they and their pupis and students will benefit from a change to a customer focus. Total quality is about more than being 'nice to customers and smiling'. It is about listening and entering into a dialogue about people's fears and aspirations." Staff harus paham bagaimana mereka dan muridnya dapat memperoleh manfaat dari fokus terhadap pelanggan. Mutu terpadu bukan sekedar 'membuat pelanggan senang dan tersenyum'. Mutu terpadu adalah mendengarkan dan berdialog tentang kekhawatiran dan aspirasi pelanggan.

Dalam Manajemen Mutu Terpadu, konsep mengenai kualitas dan pelanggan diperluas. Kualitas tidak hanya bermakna kesesuaian dengan spesifikasi-spesifikasi tertentu, tetapi kualitas tersebut ditentukan oleh pelanggan. Pelanggan itu sendiri meliputi pelanggan internal dan eksternal. Kebutuhan pelanggan diusahakan untuk dipuaskan dalam segala aspek. Dalam pendidikan yang dimaksud dengan pelanggan internal adalah guru dan staff. Sedangkan pelanggan eksternal adalah pelajar, orang tua dan masyarakat umum.

Kepuasan pelanggan adalah suatu tanggapan emosional pada evaluasi terhadap pengalaman konsumsi suatu produk atau jasa. Kepuasan pelanggan adalah tingkat perasaan seseorang setelah membandingkan kinerja (atau hasil) yang ia rasakan dibandingkan dengan harapannya. 


\section{Perbaikan Berkesinambungan}

Menurut Edward Sallis (2002:24), "to create a continuous improvement culture, managers have to trust their staff and to delegate decisions to the appropriate level to give staff the responsibility to deliver quality within their own sphere." Untuk menciptakan kultur perbaikan terus menerus, seorang manajer harus mempercayai stafnya dan mendelegasikan keputusan pada tingkatan-tingkatan yang tepat. Hal tersebut bertujuan untuk memberikan staf sebuah tanggung jawab untuk menyampaikan mutu dalam lingkungan mereka. Staf membutuhkan kebebasan kerja dalam kerangka kerja yang sudah jelas dan tujuan organisasi yang sudah diketahui.

Perbaikan berkesinambungan adalah perbaikan berulang pada segala ukuran. Dalam organisasi, apabila terjadi persoalan kritis terhadap sistem atau produk, kita perlu melakukan perubahan berulang yang berkadar terobosan. Selanjutnya, apabila yang terjadi adalah penyimpangan rutin dari standar yang ada, kita lakukan perubahan berulang yang kecil atau inkrimental. Dengan demikian istilah perbaikan berkesinambungan sama sekali tidak mengabaikan inovasi dan kreativitas atau terobosan. Dalam organisasi kita perlu melakukan perbaikan inkrimental, inovasi dan kreativitas secara berkelanjutan, yang disebut perbaikan berkesinambungan.

\section{METODOLOGI PENELITIAN}

Penelitian implementasi Manajemen Mutu Terpadu ini menggunakan pendekatan kualitatif dengan metode studi kasus eksplanatoris. Penelitian ini akan dilaksanakan di Sekolah Dasar Islam Terpadu Insan Mandiri Jakarta. Sekolah ini berlokasi di jalan Batu Merah 1, kecamatan Pasar Minggu, kodya Jakarta Selatan, Provinsi DKI Jakarta.

Waktu pelaksanaan penelitian dikelompokkan menjadi tiga kegiatan, yaitu: pertama, melakukan studi pralapangan (grand tour observation); kedua, memfokuskan penelitian (mini tour observation); dan ketiga, melakukan pengamatan partisipan (participant observation). Pra penelitian dilaksanakan sejak bulan April hingga bulan Juli 2012 dan penelitian dilaksanakan selama kurang lebih 6 bulan, yaitu Februari hingga Juli 2013.

Teknik pengumpulan data dilakukan dengan obbservasi, wawancara, dan pengkajian dokumen-dokumen yang terkait. Penentuan informan dalam penelitian ini adalah secara purposive sampling (sampel bertujuan) dan snowball sampling, yakni meminta informan menunjuk orang lain yang dapat memberikan informasi. Pemilihan key informan maupun informan berdasarkan keterlibatannya, kedudukan, tanggung jawab dan peran sertanya dalam pelaksanaan manajemen mutu terpadu.

Analisis data meliputi pengujian, pengelompokkan, memasukkan ke dalam tabel, mengetes atau menggabungkan kembali bukti-bukti atau data, untuk menggambarkan kesimpulan yang berbasis data. Pemeriksaan keabsahan data dalam penelitian ini dilakukan ke dalam beberapa kriteria, yaitu: kredibilitas (validitas internal), transferabilitas (validitas eksternal), dependabilitas (reliabilitas), dan konfirmabilitas (obyektifitas).

\section{HASIL PENELITIAN DAN PEMBAHASAN}

Temuan penelitian yang berupa data penelitian diperoleh melalui wawancara, dokumentasi dan observasi langsung tentang implementasi manajemen mutu terpadu 
di SDIT Insan Mandiri dengan sub fokus kepuasan pelanggan dan perbaikan berkesinambungan. Indikator sub fokus kepuasan pelanggan yang digunakan adalah pelayanan terhadap pelanggan, kepercayaan pemimpin terhadap bawahannya, pelanggan merasa senang, harapan pelanggan terpenuhi. Sedangkan Indikator sub fokus perbaikan berkesinambungan yaitu mengadakan pelatihan, melakukan evaluasi terus menerus, melakukan supervisi, mempekerjakan konsultan eksternal.

\section{Kepuasan Pelanggan}

Untuk indikator pelayanan terhadap pelanggan, berdasarkan hasil temuan di lapangan didapatkan informasi bahwa pelayanan terhadap pelanggan di SDIT Insan Mandiri sudah berjalan dengan baik. Pelayanan terhadap pelanggan tercermin dari pencapaian prestasi akademik yang menonjol, dibuktikan dengan berhasilnya sekolah menjadi sekolah model tingkat nasional. Di samping itu lulusan sekolah ini juga berhasil masuk di sekolah lanjutan SMP negeri. Dengan demikian dapat dikatakan bahwa pelanggan internal yaitu siswa memperoleh pelayanan dengan baik.

Berdasarkan hasil wawancara yang dilakukan terhadap pelanggan internal, guru dan karyawan, diperoleh informasi bahwa sarana prasarana dalam menunjang pekerjaan dan kegiatan belajar mengajar yang didapatkan sudah sesuai dengan harapan pelanggan internal. Selain itu dari hasil wawancara ditemukan pula, kepuasan pelanggan internal terkait pemberian gaji yang sudah sesuai dengan harapan. Edward Sallis (2002:29) menjelaskan, "staff have to understand how they and their pupis and students will benefit from a change to a customer focus. Total quality is about more than being 'nice to customers and smiling'. It is about listening and entering into a dialogue about people's fears and aspirations." Staff harus paham bagaimana mereka dan muridnya dapat memperoleh manfaat dari fokus terhadap pelanggan. Mutu terpadu bukan sekedar 'membuat pelanggan senang dan tersenyum'. Mutu terpadu adalah mendengarkan dan berdialog tentang kekhawatiran dan aspirasi pelanggan. Dalam Manajemen Mutu Terpadu, konsep mengenai kualitas dan pelanggan diperluas. Kualitas tidak hanya bermakna kesesuaian dengan spesifikasi-spesifikasi tertentu, tetapi kualitas tersebut ditentukan oleh pelanggan. Pelanggan itu sendiri meliputi pelanggan internal dan eksternal. Kebutuhan pelanggan diusahakan untuk dipuaskan dalam segala aspek. Dalam pendidikan yang dimaksud dengan pelanggan internal adalah guru dan staff. Sedangkan pelanggan eksternal adalah pelajar, orang tua dan masyarakat umum. Kepuasan pelanggan adalah suatu tanggapan emosional pada evaluasi terhadap pengalaman konsumsi suatu produk atau jasa.

Indikator kepercayaan pemimpin terhadap bawahannya juga menunjukkan hasil yang baik di mana seluruh responden pelanggan internal yang diwawancarai menyatakan bahwa mereka diberikan kebebasan oleh pemimpin untuk berkreativitas dan berimprovisasi dalam pekerjaan mereka selama masih dalam batas-batas tertentu.

Indikator pelanggan merasa senang juga menunjukkan hasil yang baik berdasarkan hasil wawancara yang dilakukan. Sementara indikator pelanggan harapan pelanggan terpenuhi juga berjalan dengan baik. Hal ini dibuktikan dengan menciptakan lingkungan yang kondusif dan menyenangkan bagi para pelanggan, terutama siswa dan tenaga pendidik serta menyiapkan sarana prasarana yang memadai bagi tenaga pendidik dalam melaksanakan tugas dan tanggung jawabnya. Penerapan sistem Manajemen Mutu Terpadu telah memberikan kontribusi, yang dapat dilihat dari adanya perbaikan berkesinambungan dan kepuasan kepada pelanggan internal dan eksternal. 


\section{Perbaikan Berkesinambungan}

Perbaikan secara berkesinambungan di SDIT Insan Mandiri Jakarta dilakukan dengan tujuan meningkatkan mutu dalam memberikan pelayanan kepada peserta didik, orang tua, tenaga pendidik, dan karyawan. Edward Sallis (2002:24) menjelaskan, "to create a continuous improvement culture, managers have to trust their staff and to delegate decisions to the appropriate level to give staff the responsibility to deliver quality within their own sphere." Untuk menciptakan kultur perbaikan terus menerus, seorang manajer harus mempercayai stafnya dan mendelegasikan keputusan pada tingkatan-tingkatan yang tepat. Hal tersebut bertujuan untuk memberikan staf sebuah tanggung jawab untuk menyampaikan mutu dalam lingkungan mereka. Staf membutuhkan kebebasan kerja dalam kerangka kerja yang sudah jelas dan tujuan organisasi yang sudah diketahui. Perbaikan berkesinambungan adalah perbaikan berulang pada segala ukuran. Dalam organisasi, apabila terjadi persoalan kritis terhadap sistem atau produk, kita perlu melakukan perubahan berulang yang berkadar terobosan. Selanjutnya, apabila yang terjadi adalah penyimpangan rutin dari standar yang ada, perlu dilakukan perubahan berulang yang kecil atau inkrimental. Lebih lanjut, temuan penelitian menunjukkan perbaikan berkesinambungan di SDIT Insan Mandiri dilakukan berdasarkan evaluasi, keluhan pelanggan, dan ketidaksesuaian dalam pelayanan. Implementasi perbaikan berkesinambungan pada SDIT Insan Mandiri dilakukan melalui (1) pelatihan-pelatihan, untuk meningkatkan kompetensi guru, (2) evaluasi terus menerus, dengan mengidentifikasi dan melakukan perbaikan dengan mengevaluasi pelaksanaan tahuntahun sebelumnya terutama 2 tahun terakhir. Namun berdasarkan pengamatan peneliti, pihak manajemen, kepala sekolah maupun guru dan staf tidak terlalu mengutamakan evaluasi kegiatan, maka akibatnya ketika mengadakan kegiatan yang sama, dapat terjadi kembali kekurangan-kekurangan yang sama dalam kegiatan sebelumnya, (3) melakukan supervisi, Berdasarkan pengamatan peneliti, perubahan yang paling menonjol adalah setiap rapat evaluasi satu pekan sekali, tenaga pendidik secara bergantian melakukan micro teaching atau presentasi yang dilihat oleh semua tenaga pendidik dan staff, dan diberikan saran dan kritik sebagai penutupnya. Evaluasi seperti itu memberikan kesempatan kepada tenaga pendidik untuk menunjukkan kemampuannya berkreativitas dalam mengajar. Sehingga tenaga pendidik dapat mengevaluasi cara pengajarannya agar semakin berkualitas, (4) dengan mempekerjakan konsultan eksternal.

\section{KESIMPULAN DAN REKOMENDASI}

Kesimpulan: Pertama, proses perbaikan berkesinambungan cukup efektif dilakukan di SDIT Insan Mandiri sejak sekolah menerapkan Manajemen Mutu Terpadu. Proses perbaikan dilakukan secara bertahap dan melalui kegiatan berulang, dimana perbaikan pada ruang lingkup manajemen lebih terencana, dilaksanakan cukup baik. Kedua, kepuasan pelanggan dapat terlaksana karena adanya evaluasi dan keluhan pelanggan. Pihak manajemen sekolah langsung tanggap dengan keluhan pelanggan internal dan eksternal. Karena didirikannya SDIT Insan Mandiri diawali dengan keinginan untuk memberikan kepuasan pada para pelanggan, khususnya guru dan murid. Ketiga, proses perbaikan berkesinambungan, dan kepuasan pelanggan yang dilakukan di SDIT Insan Mandiri menjadi lebih efektif sejak sekolah melakukan penjaminan mutu yang mengacu pada standar Manajemen Mutu Terpadu dengan menggunakan Quality Assurance (QA). 
Hal tersebut menunjukkan bahwa Manajemen Mutu Terpadu telah memberikan kontribusi dalam peningkatan manajemen mutu sekolah.

Rekomendasi: untuk menyempurnakan implementasi TQM di SDIT Insan Mandiri, Kepala SDIT Insan Mandiri beserta jajaran staf manajemen sekolah, pendidik maupun tenaga kependidikannya perlu membuat evaluasi secara tertulis setiap mengadakan kegiatan dan menjalin komunikasi yang lebih baik kepada tenaga pendidik.

\section{DAFTAR RUJUKAN}

Arini, Dorothea Wahyu. Manajemen Kualitas Pendekatan Sisi Kualitatif. Jakarta: Ghalia Indonesia, 2003.

Evans, James R. dan William M. Lindsay. The Management and Control of Quality, Seventh Edition. Canada: South Western, 2008.

Sallis, Edward. Total Quality Management in Education. London : Kogan Page, 2002.

Mukhtar, Mukhneri. Supervision: Improving Performance and Development Quality in Education. Jakarta: PPs UNJ Press, 2011.

Nasution, M. Nur. Manajemen Mutu Terpadu (Total Quality Management). Bogor: Ghalia Indonesia, 2005.

Ross, Joel E. Total Quality Management 2nd edition. Singapore: St. Lucie Press, 1995.

Bogdan, Robert C. \& Sari Knopp Biklen. Qualitative Research for Education: An Introduction to Theories and Methods, 5th ed. Boston: Pearson, 2007.

Yin, Robert K. Case Study Research Design and Methods Fourth Edition. Thousand Oaks: Sage Publications Inc, 2009.

Gryna, Frank M. et.al. Juran's Quality Planning and Analysis For Enterprise Quality 5th ed. McGraw-Hill: Singapore, 2007.

Emzir, Analisis Data: Metodologi Penelitian Kualitatif. Jakarta: Rajawali Press, 2010.

Goetsch, David L. dan Stanley B. Davis. Quality Management for Organizational Excellence 6th ed. New Jersey: Pearson, 2010.

Gryna, Frank M., et. al. Juran's Quality Planning and Analysis For Enterprise Quality 5 th ed. McGraw-Hill: Singapore, 2007.

Juran, Joseph M. dan A. Blanton Godfrey, Juran's Quality Handbook 5th ed. New York: McGraw-Hill, 1999.

Kolaser, "Similarities of Three Managing Processes" dalam Juran's Quality Handbook 5th ed., Joseph M. Juran dan A. Blanton Godfrey. New 
York: McGraw-Hill, 1999.

Moleong, Lexy J., Metodologi Penelitian Kualitatif Edisi Revisi. Bandung: Rosda, 2010.

Pike, John dan Richard Barnes, TQM in Action. London: Chapman \& Hall, 1994.

Tjiptono, Fandy dan Anastasia Diana, Quality Management Edisi Revisi. Jogyakarta: Andi, 2003.

Yin, Robert K., Case Study Research: Design and Methods 4thed. California: Sage Publications, 2009.

Yukl, Gary, Leadership in Organizations, New Jersey: Pearson, 2006. 